\title{
Working for the Best or Bracing for the Worst? Approach and Avoidance Motivation in Planning
}

\author{
Simen $B \emptyset^{1}{ }^{\text {a }}$, Hallgeir Sjåstad ${ }^{2}$, Elisabeth Norman ${ }^{3}$ \\ 1 Department of Psychosocial Science, Faculty of Psychology, University of Bergen, Bergen, Norway, ${ }^{2}$ FAIR Insight Team, SNF - Centre for Applied \\ Research at NHH, Norwegian School of Economics, Bergen, Norway, ${ }^{3}$ Department of Psychosocial Science, Faculty of Psychology, University of \\ Bergen, Bergen, Norway; Department of Psychology, Faculty of Health Sciences, University of Tromsø, Norway \\ Keywords: plans, prospection, motivation, anticipated affect, perceived distance \\ https://doi.org/10.1525/collabra.21173
}

\section{Collabra: Psychology}

Vol. 7, Issue 1, 2021

Even though planning is generally helpful in goal pursuit, people do not always choose to plan. The inclination to plan might depend on whether we focus on what we seek to approach or what we seek to avoid. In two pre-registered experiments, we tested the relative effect of approach versus avoidance motivation on willingness to plan (total $N=1349$ ). With outcome framing as the experimental manipulation, participants were randomly assigned to either an approach or an avoidance condition, and then indicated their willingness to plan their study activities before an upcoming exam. Contrary to predictions, the results showed no significant difference in willingness to plan depending on condition in either experiment. There was mixed support for the importance of anticipated affect and perceived distance as process mechanisms: While Experiment 1 showed that participants who experienced the day of the exam as closer in time were more willing to plan their study preparations (regardless of condition), we found no mediational effects through perceived distance or anticipated affect. In Experiment 2, anticipated affect intensity mediated the association between motivation and willingness to plan, where participants induced to approach motivation predicted greater intensity of anticipated affect upon achieving their goals, and thus were more willing to plan, than participants induced to avoidance motivation. However, such mediational effects without a main effect remain ambiguous and should be interpreted with caution. Seen as a whole, the results suggest that the effect of different motivation types on the willingness to plan may be different than previously thought: They may not influence this aspect of goal striving.

People spend considerable amounts of time on prospection; mentally representing how the future might turn out (Szpunar et al., 2014). One reason for thinking about future events is to plan for how to deal with them. In one study using experience-sampling methods, planning accounted for more than half of all future-related thoughts occurring in daily life (D’Argembeau et al., 2011). In another study, planning was described as the most common function of mindwandering, in which attention drifts from the current task to self-generated thoughts irrelevant to the task at hand (Stawarczyk et al., 2013). These results highlight the importance of planning in prospective thought and illustrate how people often think ahead to plan their actions.

Planning usually entails mental preparation (S. L. Friedman et al., 1987; Gollwitzer, 1996; Hayes-Roth \& HayesRoth, 1979), where self-generated thought is used to prepare for the future. This preparation may be aimed at attaining goals (S. L. Friedman et al., 1987; Mumford et al., 2001), i.e., end-points that a person wants to achieve (Per- vin, 1989). That is, rather than passively predicting what might happen in the future, planning is used to prepare for those potential outcomes in advance, ideally by identifying the steps necessary to navigate towards the most desirable end state (Baumeister et al., 2018; Seligman et al., 2013).

Despite some commonalities, different subtypes of planning can be identified. Planners engage in computational planning when solving a formal problem and errand planning when shopping for groceries (Scholnick \& Friedman, 1993). Plans can be episodic and involve specific future episodes or they can be semantic and constitute a general preparation for the future (Szpunar et al., 2014). Plans can be simple, such as if-then implementation intentions (Gollwitzer, 1996), or complex, such as a conservation plan for how to save the red panda species from extinction (Glatston, 1994). Mental simulation can occur as forward planning, starting with the step closest to the present, or as backward planning, starting from the step closest to the goal (Park et al., 2017). In all these different forms of planning, 
mental preparation for outcomes seems crucial. As such, we define planning as the intentional formulation of necessary steps to reach a specific goal in the future.

\section{Motivation and Planning}

Given that people make plans quite frequently, they may have different reasons for doing so. Often, people make plans because it has a pragmatic, guiding effect on actions that bring about desirable outcomes (Baumeister et al., 2018), for example by directing attention to important information (Dewhurst et al., 2019). Research demonstrating that planning contributes to goal attainment supports this notion (Gollwitzer \& Sheeran, 2006). However, people do not automatically make plans for their goals (Gollwitzer, 1996), and planning may be only one of several strategy choices (Ellis \& Siegler, 1997) that people use for goal attainment (e.g. choosing to pursue a goal without a determined plan would also be a strategy choice). Given the usefulness of planning, it is of great importance to further explore why people choose to plan.

People may have different sources of motivation for making plans. For instance, some researchers have emphasized the importance of beliefs (Day \& Maltby, 2005; Kreitler \& Kreitler, 1987), in the sense that people may be more willing to plan if they believe that planning is normatively appropriate. Others have focused on perceived control, based on the assumption that people typically make plans for those events they think they can control (Doron et al., 2009; S. L. Friedman et al., 1987). Still others have shown that the willingness to plan requires self-control (Sjåstad \& Baumeister, 2018), which implies that people may avoid planning because it is mentally exhausting. Despite some previous research of this kind, the subject of motivation in planning remains underexplored (Ward \& Morris, 2005). It is particularly unclear how specific motivational states influence the willingness to plan. Across two experiments, the current investigation aims to address this knowledge gap by looking at approach versus avoidance motivation as potential explanations of why people choose to make plans.

Approach motivation occurs when positive stimuli energize or direct behavior, whereas avoidance motivation occurs when negative stimuli energize or direct behavior (Elliot, 2008). Although there is a general correspondence between valence and motivation, negatively valenced outcomes may also motivate approach behavior (i.e. anger, as a negative emotion, is associated with approach behavior; Harmon-Jones, 2003). Stimuli may energize behavior by shifting priorities between tasks and direct behavior by guiding it toward specific stimuli (Elliot, 2006). Approach motivation is associated with more positive thoughts and more frequent success in goal striving (Tamir \& Diener, 2008). In contrast, avoidance motivation is associated with more negative thoughts in goal striving (Tamir \& Diener, 2008) and may negatively affect self-regulation (Oertig et al., 2013). Through their influence on goal striving (Elliot \& Church, 1997), both approach and avoidance motivation may influence how willing people are to plan. A central question, then, is whether one of them exerts a stronger impact than the other.

\section{Competing Motivational Systems: Approach vs. Avoidance}

Goal orientations. Results from several different research areas have differing implications regarding the relative impact of approach versus avoidance motivation on planning. Some studies have shown positive associations between approach goals and planning, measured as a component of metacognition for developing group plans (Mehta et al., 2009). Similar associations have been reported in studies measuring planning as a sub-category of self-regulation for writing (Kaplan et al., 2009). However, others have shown positive associations between avoidance goals and planning, measured as metacognition in physical education (Papaioannou et al., 2009). Yet others have reported no relationship between approach-oriented imagery and plans for physical activity (Chan \& Cameron, 2012). These diverging results suggest a need for studies that test bi-directional competing hypotheses about the effects of approach versus avoidance motivation on willingness to plan.

To the best of our knowledge, only one experimental study in the literature on goal orientations has explored how these orientations might influence planning. Here, participants completed two learning tasks using a hypermedia environment, where they could freely explore information about biological systems (Moos \& Azevedo, 2006). All participants performed their first learning task in a mastery goal condition. For a second learning task, participants were randomly assigned to either a mastery goal condition, a performance-approach goal condition or a performanceavoidance goal condition. Specifically, participants were given instructions that emphasized their own learning (mastery condition), the possibility of performing better than other students (performance-approach condition) or the possibility of performing worse than other students (performance-avoidance condition). Self-regulation was assessed using a think-aloud paradigm, where statements coded as prior knowledge activation or recycling of goals in working memory were classified as planning. Only participants in the performance-avoidance condition showed more planning in the second learning task than the first, suggesting that avoidance motivation had a stronger influence on planning than approach motivation. However, one could argue that prior knowledge activation may be pastoriented, differing from planning's prospective nature. Also, some researchers (O'Hara \& Payne, 1998) have argued that recycling of goals reflects a person's intention and not their planning. These concerns suggest that participants' statements may not have been indicative of planning. As the question of which motivational state has the strongest impact on planning seems to remain unanswered, we conclude that competing bi-directional hypotheses are warranted.

Regulatory focus. Another area of research that helps guide competing hypotheses on the effects of motivational states on planning is research on regulatory foci; different ways to regulate the tendencies to approach pleasure and avoid pain (Higgins, 1996). Regulatory focus theory distinguishes between two foci: promotion focus, which orientates towards the presence or absence of positive outcomes, and prevention focus, which orientates toward the presence 
or absence of negative outcomes (Higgins \& Spiegel, 2004). Regulatory foci are assumed to exist both as relatively permanent traits and experimentally inducible temporal states (Higgins \& Spiegel, 2004). A person can engage in both approach and avoidance motivation in both regulatory foci (Higgins, 2012). However, some studies suggest that certain measures of regulatory foci overlap with measures of approach and avoidance (Summerville \& Roese, 2008). Also, researchers commonly manipulate regulatory focus by emphasizing approach (promotion focus) or avoidance (prevention focus; e.g. Peng et al., 2011).

Trait-level promotion focus has been shown to predict future time perspective, defined as individual differences in orienting toward future outcomes (Andre et al., 2017). Future time perspective encompasses willingness to plan, suggesting an association between approach motivation and planning. Nevertheless, other studies have shown that trait prevention focus predicts self-reported planning of dietary intake (Vartanian et al., 2006) and trait promotion focus predicts impulsiveness, defined as self-reported spontaneous purchases (Das, 2015). Thus, the diverging results give further support to competing, bi-directional hypotheses about the effects of approach and avoidance motivation on the willingness to plan.

We have been able to identify only one experimental study (Peng et al., 2011) that has specifically addressed the effects of regulatory foci on planning. This study involved a negotiation setting where participants were randomly assigned to receiving either a promotion or prevention goal for the negotiation outcomes. They received a planning worksheet as part of their preparation for the negotiation. After the negotiation, the worksheet was coded for the number of negotiation strategies, thought to reflect thorough planning, and whether participants had included all negotiable issues, thought to reflect comprehensive planning. On both measures, participants in the prevention condition scored higher than those in the promotion condition. This suggests that avoidance motivation may influence planning more strongly than approach motivation. Nevertheless, the manipulation check of the experimental induction showed that participants in both conditions were relatively promotion-oriented. This suggests that the results may be more illustrative of how people plan under varying degrees of approach motivation than of how they plan differently for approach and avoidance.

To summarize the research on motivational states and planning, there are grounds for assuming both that 1) approach motivation could influence willingness to plan more than avoidance motivation and that 2) avoidance motivation could influence willingness to plan more than approach motivation. Competing, bi-directional hypotheses about the effects of motivational states on willingness to plan thus reflects divergent findings in previous research. The present experiments were therefore designed as targeted experimental tests of the competing, bi-directional hypotheses.

\section{Manipulating Motivational States and Measuring Planning}

Manipulating approach and avoidance motivation.
In previous research, motivational states have been induced with muscular movements, physical sensations, emotions, scent, music, and outcome framing (Aarts et al., 2010; Crawford et al., 2013; R. S. Friedman \& Förster, 2000; Mattila \& Wirtz, 2001; Roskes et al., 2012; Spangenberg et al., 2006). The suitability of these manipulations may differ depending on the context of the study. For example, using scent and music may be more conducive in field experiments, whereas muscular movements and outcome framing could be more applicable in controlled experimental settings.

Because of the importance of specific outcomes for planning, we suggest that outcome framing, highlighting the outcome as something to be approached or avoided, is a suitable manipulation that can be targeted experimentally to induce either approach or avoidance motivation. In some previous research, researchers have used participants' personally idiosyncratic goals to measure approach and avoidance motivation (e.g. Dickson \& MacLeod, 2004, 2006; Winch et al., 2015). However, while this procedure is clearly optimal for measuring participants' idiographic approach and avoidance goals, using this procedure to manipulate approach and avoidance motivation might introduce an additional confound related to possible differences in goal content, which might differ between the conditions. This would introduce more uncontrolled variation in a controlled test of the motivational effects. We argue that another manipulation that is also suitable is to present participants with a relevant, pre-defined goal and ask them either to focus on what they want to achieve related to this goal or what they want to avoid related to this goal. Similar experimental manipulations (outcome framing) have been used to successfully manipulate motivational states in previous research (Aaker \& Lee, 2001; Detweiler-Bedell \& Salovey, 2003), supporting the use of such an experimental manipulation of motivational states. Owing to its applicability and demonstrated effectiveness, we used an outcome framing in the form of framed goals to manipulate approach and avoidance motivation in the current experiments.

Measuring planning. Researchers operationalize planning differently, and some measures reflect general futurethinking or goal-setting. For example, the Motivated Strategies for Learning Questionnaire refers to planning as “setting goals" (Pintrich et al., 1993, p. 803) and as "task analysis” (Pintrich et al., 1991, p. 23). Both can precede planning but do not directly involve generating necessary steps to reach a goal. This makes it necessary to use a different operationalization of planning for the current experiments.

One form of planning that allows for such an operationalization is action planning. Action planning involves specifying when, where, and how to perform actions that could help in goal attainment, as well as how much time to spend on these actions (Sniehotta et al., 2005). It is distinct from coping planning, which involves planning for how to meet obstacles that may hamper goal pursuit (Sniehotta et al., 2005). Action planning reflects a well-grounded theoretical understanding of planning in the form of implementation intentions, though there are certain differences (Hagger \& Luszczynska, 2014). Scores on measures of action planning have been shown to predict academic goal 
progress (Carraro \& Gaudreau, 2011), and as planning is assumed to be beneficial to goal progress, this supports the construct validity of this measurement (Meltzoff \& Cooper, 2018). As the outcome measure in the current experiments, we measured willingness to plan using an adapted measure of action planning, aimed toward how willing people are to plan their future behavior to reach a specific goal.

\section{Mechanisms: Anticipated Affect and Perceived Distance}

In addition to exploring an effect of motivational states on willingness to plan, the current investigation also addresses whether anticipated affect and perceived distance can explain such an effect. Specifically, we suspected that anticipated affect and perceived distance might serve as mediators that co-produce the causal effect from motivational state to willingness to plan (Hayes, 2009).

Anticipated affect or affective forecasting refers to predictions about feelings resulting from future events (Miloyan \& Suddendorf, 2015; Wilson \& Gilbert, 2005). Because people usually approach happiness and avoid unhappiness, anticipated happiness and unhappiness map onto the approach-avoidance distinction, suggesting that how people expect to feel may be influenced by motivational states. Also, anticipated affect has been shown to influence decisionmaking (DeWall et al., 2016; Mellers et al., 1999) as well as motivation and performance (Greitemeyer, 2009; Greitemeyer et al., 2011; Morewedge \& Buechel, 2013), suggesting that anticipated affect could influence willingness to plan. These conceptual and empirical relationships identify anticipated affect as a possible mechanism explaining the predicted effect of motivational states on willingness to plan.

Perceived temporal distance concerns how close, or how far away, something feels from the present moment (Peetz et al., 2009). In one theory of perceived distance, Balcetis (2016) argues that approach motivation decreases perceptions of distance, whereas avoidance motivation increases perceptions of distance. Even though the theory primarily concerns spatial distance, there are both theoretical (Trope \& Liberman, 2010) and empirical (Parkinson et al., 2014) reasons to assume similarities between different forms of psychological distance. This suggests that approach and avoidance motivation could influence perceived temporal distance in a similar manner to spatial distance. Also, in one study, participants induced to experience the future as closer reported greater motivation for their academic goals than participants induced to experience the future as further away (Peetz et al., 2009). If motivational states can influence perceived temporal distance, and perceived distance can influence willingness to plan, the effect of motivational state on willingness to plan could at least in part be explained by perceived distance. For example, a student focusing on the grade he or she wishes to attain on an exam might perceive the day of the exam as closer than a student focusing on the grade he or she wishes to avoid, making the first student more willing to plan to reach the goal.

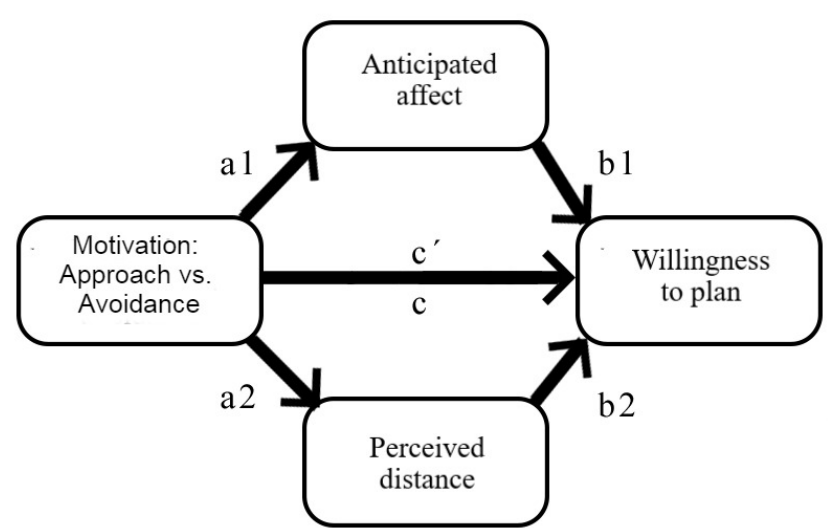

\section{Figure 1: The parallel mediation model tested in the current experiments}

The symbols a1 and a2 represent the effects of motivational state on the mediators. The symbols b1 and b2 represent the effects of the mediators on willingness to plan. The symbol c' represents the direct effect of motivational state on willingness to plan, whereas the symbol c represents the indirect effect of motivational state on willingness to plan through the mediators.

\section{Overview}

The present experiments explored approach and avoidance motivation as psychological antecedents to the willingness to plan future actions. The research question concerns whether willingness to plan is greater for approach motivation or greater for avoidance motivation, and whether an effect of this kind can be explained by anticipated affect and perceived distance. We pre-registered the hypotheses, methods, measures and statistical analyses before collecting data (Appendix S1 and S2). Pre-registration helps distinguish between confirmatory and exploratory analyses (Nelson et al., 2018) and helps prevent conclusions drawn from insufficient evidence (Hales, 2016). In this way, it can help improve the robustness and replicability of empirical research. Changes to the experiments that deviate from the pre-registrations are noted in Appendix S3, and non-registered exploratory analyses are described as such in the results.

The two experiments were conducted as between-subjects experiments in an online survey (double-blind) with random assignment to one of two conditions: approach or avoidance motivation. Potential mediation through anticipated affect and perceived distance was assessed in a parallel mediation model (see Fig 1). As willingness to plan could be influenced by years of prior education (Prenda \& Lachman, 2001), mood (Phillips et al., 2002), prior grades and the number of days until the exam, these variables were also measured to potentially be used as covariates in the analyses. We also explored age and gender as potential covariates.

\section{Experiment 1}

\section{Hypotheses}

The specific hypotheses for the first experiment are listed below: 
- H1a: Approach motivation will lead to a greater willingness to plan than avoidance motivation.

- H1b: Avoidance motivation will lead to a greater willingness to plan than approach motivation.

- Mediation hypothesis 1: The greater effect of approach (versus avoidance) motivation, as predicted by $\mathrm{H} 1 \mathrm{a}$, will be mediated by a greater intensity of anticipated affect in the approach condition than the avoidance condition.

- Mediation hypothesis 2: The greater effect of avoidance (versus approach) motivation, as predicted by $\mathrm{H} 1 \mathrm{~b}$, will be mediated by a greater intensity of anticipated affect in the avoidance condition than the approach condition.

- Mediation hypothesis 3: Perceived temporal distance will mediate the relationship between motivational state and willingness to plan, where approach motivation will cause participants to perceive the day of the exam as temporally closer, and avoidance motivation will cause participants to perceive the day of the exam as temporally further away.

\section{Method}

\section{Participants}

Based on a statistical power analysis using $\mathrm{G}^{*}$ Power software (Faul et al., 2007), the planned sample size was a minimum of 200 participants, which provides $80 \%$ power to detect a moderate main effect $(d=0.4)$. The power analysis was based on the main hypothesis in this experiment (i.e., the predicted group difference in willingness to plan between participants in the approach and avoidance condition). To plan for potential dropouts and incomplete responses, we recruited a convenience sample of 262 students in the break of a lecture or prior to the end of a lecture $(88$ men, 143 women, 31 who did not wish to indicate their gender, $M_{\text {age }}=21.69, S D_{\text {age }}=3.41$ ). The experiment was conducted online using Qualtrics (2018 Version) in which the participants completed the survey while seated in the auditorium.

\section{Procedures}

Participants took part in what was described as a study on thoughts and feelings about exams. To reduce the influence of potential demand characteristics, hypotheses were not disclosed (Orne, 1962). Because of anonymity ensured by not registering participants' IP-address in Qualtrics, in accordance with the Data Protection Official for Research in Norway, the data were not covered by the Norwegian Personal Data Act, and the project was thus exempt from submitting a formal application to the Data Protection Official for Research. Furthermore, as the experiment did not explore research questions related to health, there was no requirement to formally apply to the Regional Committee for Medical and Health Research Ethics, as the experiment was not covered by the Norwegian Health Research Act. Participants marked their informed consent before participation, in accordance with the Declaration of Helsinki (World Medical Association, 2013). The participants received a written debrief explaining the purposes of the experiment after completing the questionnaire.

Participants indicated their age and gender ("What is your biological gender?") with the alternatives "man", "woman", and "do not wish to report" before the experimental manipulation, where they were randomly assigned to an approach $(n=112)$ or an avoidance $(n=114)$ condition. Participants in the approach (avoidance) condition were told that many students set goals based on the grade they try to achieve (avoid). Moreover, they were instructed to think about which grade they would attempt to achieve (avoid) on their exam in the subject they had a lecture in. They were then asked to write their goal using the words "I will try to achieve (avoid) the grade X or better (worse) on my exam in this subject". Thus, instructions were designed to encourage participants to focus either on a future outcome they wanted to approach or a future outcome they wanted to avoid.

\section{Measures}

After the experimental manipulation, participants responded to the two questions used as mediator measures (anticipated affect and perceived distance) and the questions used as the outcome measure (willingness to plan). For the first mediator variable, participants in the approach (avoidance) condition were asked to predict their feelings about receiving the grade they were trying to attain (avoid) or better (worse). For both measures, responses were indicated on an 11-point scale from -5 (very unhappy) to +5 (very happy), adapted from Li et al. (2012).

For the second mediator, perceived distance, participants were asked "How far away does the day of the exam feel?" with responses indicated on an 11-point scale from 0 (feels like the day of the exam is tomorrow) to 10 (feels like the day of the exam is far away), adapted from Peetz et al. (2009). The order of presentation for the two mediator measures was counterbalanced to avoid order effects.

Willingness to plan was measured with a four-item scale of action planning adapted from Åstrøm (2008). This scale assessed participants' willingness to plan for when, where, how, and how much time they were going to spend preparing for the exam. The items were on a 7 -point scale $(1=$ totally disagree, $4=$ neither agree nor disagree, $7=$ totally agree) (I am willing to make a detailed plan for when/where/ how I am going to read until the exam; I am willing to make a detailed plan for how much time I am going to spend reading until the exam). The four-item measure of action planning has previously produced internally consistent scores, Cronbach's $\alpha=.95$ (Åstrøm, 2008). In the current sample the internal consistency was lower (Cronbach's $\alpha=.679$ ) and one of the items ("where") had a low item-total correlation $(r=.277)$. Due to the low item-total correlation, this item was removed. The remaining items (when, how, and how much time) were combined into a revised scale of action planning. Scores on the revised scale had acceptable internal consistency (Cronbach's $\alpha=.726$ ), considering the sample size and the number of items (Ponterotto \& Ruckdeschel, 2007).

Mood, which was included as a potential covariate, was measured using a Norwegian translation of the Worcester Affect Scale (Rhoden \& West, 2010). Participants were 
asked how positive or negative their current feelings were on an 11 -point scale $(0=$ not at all positive, $10=$ extremely positive; $0=$ not at all negative, $10=$ extremely negative). Also, participants answered a question about which grade they received on their previous exam (A-F). The number of days until the exam was assessed using public information about exam dates. Finally, a comprehension check was administered, asking participants to indicate whether they had been asked to set an approach or an avoidance goal at the beginning of the questionnaire. This was done to control for whether participants had read and understood the instructions for the experimental manipulation.

\section{Results}

\section{Data Preparation and Preliminary Analyses}

We excluded 36 participants who had incomplete responses due to not having completed any questions beyond indicating their informed consent (these participants were thus not randomized to conditions). Thus, 226 participants were randomized either to the approach $(n=112)$ or the avoidance $(n=114)$ conditions. We excluded an additional 14 participants who had incomplete responses due to either not having completed any questions beyond indicating their informed consent or not having followed the instructions for the experimental manipulation (i.e. writing down which goal they wanted to achieve or avoid). None of the excluded participants had answered the comprehension check at the end of the survey. After exclusions, the final sample used for analyses consisted of 212 participants: 105 participants in the approach condition (39 men) and 107 participants in the avoidance condition (42 men). This number of participants is in accordance with the pre-registered power analysis. IBM SPSS Version 25 was used for all analyses.

The only manipulation check included in the pre-registration was the comprehension check, which was designed as an exclusion criterion. However, the procedure also included an additional measure of the efficiency of the manipulation. This was the grades that participants in the two conditions reported when they were asked to focus on what they wanted to approach or what they wanted to avoid. Specifically, participants were asked to report a grade from A-F which they wanted to achieve or avoid. Here, the results provide a strong indication that the manipulation worked as intended: Participants in the approach condition typically focused on a much better grade (i.e., what they wanted to achieve) than the typical grade the participants in the avoidance condition focused on (i.e., what they wanted to avoid). Specifically, participants asked to focus on what they wanted to approach tended to focus more on the grades at the higher end of the scale $(M=3.75, S D=0.92$, in which $\mathrm{A}=$ 5 and $\mathrm{F}=0$ ), and participants asked to focus on what they wanted to avoid tended to focus more on the grades at the lower end of the scale $(M=2.74, S D=0.95)$. An independent t-test showed that this difference between conditions was significant, $t(210)=7.881, p<.001$, and the estimated effect size was very large, $d=1.08$.

The anticipated affect variable was recoded to reflect anticipated affect intensity, by reversing the values for the avoidance condition and combining the variable in the ap- proach and avoidance condition. So, for example, after the recoding, one participant answering +4 in the approach condition and another participant answering -4 in the avoidance condition would both have +4 in the recoded variable, reflecting the intensity of their anticipated affect as the distance from the neutral midpoint of the scale.

The presence of univariate outliers on the willingness to plan sum scale, the perceived distance score and the anticipated affect intensity score was assessed using z-scores. Three z-scores for the anticipated affect intensity variable were below -3.29. After recoding, these participants reported negative values of anticipated affect, suggesting either that they predicted that they would feel unhappy if they received the grade they wanted (approach condition) or that they predicted that they would happy if they received the grade they did not want (avoidance condition). As it was deemed probable that these participants had misunderstood the instructions, for example by mentally reversing the scales, data from the three participants were excluded from the analysis in which the anticipated affect variable was included (the mediation analysis). The mediation analysis was run both with and without the identified outliers. These did not significantly influence the results of the analysis, and thus, the solution with excluded outliers was kept.

While analyzing the relationship between willingness to plan and the control variables, the previously identified outliers were not excluded (as the exclusions concerned the anticipated affect variable). There was no significant association between willingness to plan and any of the control variables positive mood, negative mood, age, previous grade or the number of days until the exam (Table 1). As most participants had completed less than one full year of higher education, this variable was dichotomized to distinguish between those who had completed either less than or more than one year of higher education. There was no significant difference in willingness to plan depending on higher education, $t(202)=0.069, p=.945$. As such, all the preceding variables were not controlled for in subsequent analyses for the main hypotheses. There was a significant gender difference in willingness to plan, $t(210)=-2.022, p$ $=.044, d=-0.29,95 \%$ CI [-0.78, -0.10$]$, indicating that men $(M=4.53, S D=1.43)$ reported less willingness to plan than women $(M=4.93, S D=1.34)$. Controlling for gender in the analyses testing the main hypotheses did not substantially alter the results, and subsequent analyses are reported without gender as a covariate.

\section{The Effect of Motivation on Willingness to Plan}

The main hypothesis in this experiment concerned the potential effect of motivational type on willingness to plan. In contrast to the central research hypothesis, there was no significant effect of condition on willingness to plan, $t(210)$ $=-0.764, p=.446, d=0.08,95 \%$ CI [-0.52, 0.23]. Participants in the approach condition $(M=4.70, S D=1.41)$ did not differ significantly from participants in the avoidance condition $(M=4.85, S D=1.37)$ in their self-reported willingness to plan for future exam preparations. Thus, neither of the different types of motivational states appeared to have a dominant effect on participant's willingness to make plans. 
Table 1: Correlations (r) Between Control Variables and Willingness to Plan

\begin{tabular}{|l|l|l|l|}
\hline Measure & $\boldsymbol{r}$ & $\boldsymbol{p}$ & $\mathbf{9 5 \% \mathrm { Cl }}$ \\
\hline Positive Mood & .023 & .738 & {$[-.088, .032]$} \\
\hline Negative Mood & .005 & .947 & {$[-.080, .086]$} \\
\hline Age & -.064 & .357 & {$[-.710, .036]$} \\
\hline Previous Grades & .125 & .069 & {$[-.011, .283]$} \\
\hline Days Until Exam & -.043 & .539 & {$[-.006, .003]$} \\
\hline
\end{tabular}

Table 2: Independent T-Tests for Positive and Negative Mood

\begin{tabular}{|l|l|l|l|l|l|}
\hline & \multicolumn{2}{|c|}{ Condition } & & \\
\hline & Approach & Avoidance & $t$ & $d f$ & $p$ \\
\hline Positive Mood & $6.70(1.93)$ & $6.98(2.11)$ & -0.995 & 210 & .321 \\
\hline Negative Mood & $4.64(2.29)$ & $4.32(2.25)$ & 1.027 & 210 & .306 \\
\hline
\end{tabular}

Note. Numbers are mean values on an 11-point scale (0-10). Standard deviations (SD) appear in parentheses to the right of means.

\section{Mediation Analysis}

In the next step, we conducted the pre-registered mediation analyses, as a significant main effect is not required for meaningful mediation to occur (Hayes, 2013; but see also Bullock et al., 2010). To test the specific mediation hypotheses in the current investigation, we performed a parallel mediation analysis $(n=209)$ using Model 4 in PROCESS (Hayes, 2013). Motivational state was entered as the independent variable, anticipated affect intensity and perceived distance were entered as the mediators, and willingness to plan as the dependent variable. The mediation hypotheses were tested with 10,000 bootstrap samples and unstandardized effects are reported.

Participants in the approach condition reported a significantly greater intensity of anticipated affect than participants in the avoidance condition $\left(a^{1}=-0.64, p<.001\right.$, 95\% CI [-1.02, -0.26]). Greater intensity of anticipated affect was not, however, significantly associated with willingness to plan $\left(b^{1}=0.13, p=.058,95 \%\right.$ CI $\left.[-0.004,0.26]\right)$. A biascorrected bootstrap confidence interval for the indirect effect of motivational state through anticipated affect $\left(a b^{1}=\right.$ -0.083), holding the indirect effect through perceived distance constant, was not significant (95\% CI [-0.14, 0.001]). As such, the effect of motivational state on willingness to plan was not mediated by the intensity of anticipated affect.

Motivational state had no significant effect on perceived distance $\left(a^{2}=0.49, p=.199,95 \%\right.$ CI $\left.[-0.26,1.24]\right)$. However, perceived distance was significantly associated with a reduced willingness to plan $\left(b^{2}=-0.081, p=.021,95 \% \mathrm{CI}\right.$ $[-0.15,-0.01])$, meaning that shorter (as opposed to longer) perceived distance to the day of the exam was positively correlated with willingness to make plans. A bias-corrected bootstrap confidence interval for the indirect effect of motivational state through perceived distance $\left(a b^{2}=-0.394\right)$, holding the indirect effect through anticipated affect intensity constant, was not significant $(95 \% \mathrm{CI}=-0.13,0.02)$.
Thus, the effect of motivational state on willingness to plan was not mediated by perceived distance.

\section{Exploratory Analyses}

Participants in the approach and avoidance condition did not differ significantly in either positive or negative mood (Table 2), suggesting that participants' self-reported feelings did not vary as a function of whether they focused on what they wanted to approach or what they wanted to avoid.

\section{Discussion}

The first experiment explored approach and avoidance motivation as psychological antecedents to planning. Contrary to our predictions, there was no difference in the willingness to plan between participants in the two experimental conditions, suggesting that people do not plan differently for what they want to approach compared to what they want to avoid. Partly in line with our initial hypothesis for anticipated affect, participants in the approach condition reported more intense anticipated affect than participants in the avoidance condition. However, contrary to the hypothesis, this intensity was not associated with their willingness to plan. Contrary to our hypothesis, there was no difference in perceived distance between participants in the two conditions. However, regardless of condition, perceived distance was associated with willingness to plan: Participants who experienced the day of the exam as closer were more willing to plan their future behavior.

The lack of a difference in willingness to plan between the two experimental conditions could be due to the effect of motivational states being different than predicted. Another explanation is that the experimental manipulation of motivational state was less effective than intended. However, the non-registered manipulation check provides ev- 
idence that the manipulation did indeed seem to work as intended. Because the pre-registered comprehension check was placed at the end of the questionnaire, we cannot exclude the possibility that at least some participants may have misremembered the instructions when answering this question. In contrast, the non-registered manipulation check was placed immediately after the instruction and can therefore be considered a more direct measure of whether participants did what had been asked of them: focusing on what they wanted to approach or avoid. In our view, this may serve as a more valid manipulation check than the measure we pre-registered. Whereas the comprehension check focused on participants' memory of what they were asked to do, the manipulation check we describe here was more likely to reflect participants' ongoing thoughts about what they wanted to approach or avoid when reporting their willingness to make plans.

Despite some empirical support for the effectiveness of the experimental manipulation, one counterargument would be that the manipulation check did not directly assess variation in the independent variable: The motivational state. The fact that there were no differences in positive or negative mood depending on condition, despite the assumption that approach and avoidance could influence mood (Coats et al., 1996), lends some support to the assumption that the experimental manipulation was not effective. To address this and other limitations in the original experiment, we designed a second experiment with a stronger test of the original hypotheses.

\section{Experiment 2}

\section{Hypotheses}

The second experiment was conducted as a replication to test the original hypotheses in a high-powered experiment, and to include measures which allows the exclusion of some alternative explanations. We included a more appropriate manipulation check, a measure of the perceived personal relevance of the goal for the experimental manipulation, and a measure of the time of completion of the survey. In addition, the sample size was larger. The hypotheses for Experiment 2 were the same as for Experiment 1, with one important exception: We specified our hypothesis for the first mediator, which we failed to do in the pre-registration for the first experiment. Specifically, the mediation hypothesis for anticipated affect intensity was specified to also describe the proposed relationship between the mediator and the dependent variable explicitly:

- H1a: Approach motivation will lead to a greater selfreported willingness to plan than avoidance motivation.

- H1b: Avoidance motivation will lead to a greater selfreported willingness to plan than approach motivation.

- Mediation hypothesis 1: If results are as predicted by $\mathrm{H} 1 \mathrm{a}$, the greater effect of approach motivation will be mediated by a relatively greater intensity in anticipated positive affect in this condition, as compared to the intensity of anticipated negative affect in the avoidance condition. In turn, a higher intensity of anticipated affect will be associated with a stronger willing- ness to plan.

- Mediation hypothesis 2: If results are as predicted by $\mathrm{H} 1 \mathrm{~b}$, the greater effect of avoidance motivation will be mediated by a relatively greater intensity in anticipated negative affect in this condition, as compared to the intensity of anticipated positive affect in the approach condition. In turn, a higher intensity of anticipated affect will be associated with a stronger willingness to plan.

\section{Method}

\section{Participants}

Based on a statistical power analysis using $G^{*}$ Power software (Faul et al., 2007), the a priori planned sample size was a minimum of 352 participants, which provides $80 \%$ power to detect a small-to-moderate main effect $(d=0.3)$. The power analysis was based on the main hypothesis in this experiment (i.e., the predicted group difference in willingness to plan between participants in the approach and avoidance condition). To plan for potential dropouts and incomplete responses, we preregistered a planned sample size of 400 students. Due to an unexpectedly large turn-out in the first days of data collection, the final convenience sample consisted of 1087 students (231 men, 792 women, $M_{\text {age }}=23.80$, $\left.S D_{\text {age }}=5.31\right)$. Participants were recruited through e-mail lists, student forums and social media aimed at students at the University of Bergen in Norway. The experiment was conducted online using Qualtrics (2020 Version).

\section{Procedures}

The experimental procedure was the same as in Experiment 1: Participants took part in what was described as a study on thoughts and feelings about exams. Participants indicated their age and gender ("What is your biological gender?”) with the alternatives "man”, “woman”, and "do not wish to report" before the experimental manipulation, where they were randomly assigned to an approach $(n=$ $478)$ or an avoidance $(n=465)$ condition, using the same experimental manipulation as in Experiment 1. After the experimental manipulation, participants were administered a manipulation check, asking them to which extent they were thinking about the grade that they wanted to achieve (approach condition) or avoid (avoidance condition) right now $(0=$ not at all, $5=$ to some extent, $10=$ to a very large extent). Thus, more clearly than in the first experiment, this manipulation check directly addressed participants' motivational states.

\section{Measures}

After the experimental manipulation, participants responded to the same mediator measures as in Experiment 1 (anticipated affect and perceived distance) and the same outcome measure as in Experiment 1 (willingness to plan). The four-item measure of action planning used in both experiments has previously produced internally consistent scores, Cronbach's $\alpha=.95$ (Åstrøm, 2008). In the current sample, the internal consistency was lower in a similar manner as in Experiment 1 (Cronbach's $\alpha=$.655). However, 
Table 3: Correlations (r) Between Control Variables and Willingness to Plan

\begin{tabular}{|l|l|l|l|}
\hline Measure & $\boldsymbol{r}$ & $\boldsymbol{p}$ & $\mathbf{9 5 \%} \mathrm{Cl}$ \\
\hline Positive Mood & .053 & .141 & {$[-.017, .122]$} \\
\hline Negative Mood & .019 & .601 & {$[-.051, .089]$} \\
\hline Age & -.057 & .110 & {$[-.126, .013]$} \\
\hline Previous Grade & -.012 & .746 & {$[-.085, .061]$} \\
\hline Years of Higher Education & -.077 & .033 & {$[-.147,-.006]$} \\
\hline
\end{tabular}

in contrast to Experiment 1, none of the items had a particularly low item-total correlation (all items above .3). Thus, all items were combined into a scale of action planning.

The measures of positive and negative mood, previous grade and the comprehension check were all the same measures as in Experiment 1. Additionally, for exploratory purposes, we asked participants to indicate the personal relevance of the goal in the experimental manipulation (How personally relevant do you think the goal for the exam grade is for you; $0=$ not at all relevant, 10 = very relevant), their expected grade for the exam in the subject they set a grade goal for (A-F), and a question assessing at what time they completed the survey (1) preceding a lecture; 2 ) in the break of a lecture; 3 ) after a lecture; 4) independent of any lecture).

\section{Results}

\section{Data Preparation and Preliminary Analyses}

We excluded 223 participants who had incomplete responses, due to not having answered the comprehension check at the end of the experiment. Additionally, we excluded 77 participants who answered the comprehension check wrongly according to condition, either indicating that they had been asked to set an approach-goal when they were really asked to set an avoidance-goal $(n=56)$ or that they had been asked to set an avoidance-goal when they were really asked to set an approach-goal $(n=21)$. This left a total of 787 participants for analyses ( $n=419$ in the approach condition, $n=368$ in the avoidance condition). This sample is almost four times as large as the final sample in Experiment 1 and provided $80 \%$ power to detect a relatively small effect ( $d=0.2$, two-tailed). Experiment 2 can therefore be considered a high-powered replication.

We conducted two one-sample t-tests on the scores on the manipulation check to assess whether participants had been successfully induced to an approach or avoidance motivational state. Participants' average scores were compared with a value of 4 (i.e. below the midpoint value of 5 : «to some extent»). In line with our expectations, participants in the approach-condition $(M=6.44, S D=2.39)$ were thinking about the grade they wanted to achieve to some extent or greater, $t(418)=20.89, p=<.001, d=1.02,95 \%$ CI [2.21, 2.67]. Similarly, participants in the avoidance-condition $(M$ $=5.24, S D=2.62$ ) were thinking about the grade they wanted to avoid to some extent or greater, $t(367)=9.07, p=$ $<.001, d=0.47,95 \%$ CI $[0.97,1.50]$. Specifically, $84.8 \%$ of participants in the approach-condition indicated that they were thinking about the grade they wanted to achieve "to some extent" (5) or more (6-10), whereas $67.6 \%$ of participants in the avoidance-condition indicated that they were thinking about the grade they wanted to avoid to "some extent" (5) or more (6-10).

The anticipated affect variable was recoded to reflect anticipated affect intensity, just like the recoding described in Experiment 1. In accordance with our pre-registration, only the scores for participants answering in conflict with the experimental condition to which they were assigned on the comprehension check were excluded. The mediation analysis was run both with and without the identified outliers. These did not significantly influence the results of the analysis, and thus, the solution with included outliers was kept.

There was no significant association between willingness to plan and any of the control variables positive mood, negative mood, age or previous grade (Table 1). There was, however, a significant association with years of higher education: Participants reporting a higher number of years of education were less willing to plan. Controlling for years of higher education in the main analyses did not change the results, and subsequent analyses are reported without higher education as a covariate. There was a significant gender difference in willingness to plan, $t(230.53)=-4.01, p<.001$, $d=0.37,95 \%$ CI $[-0.710,-0.240]$, indicating that men reported less willingness to plan $(M=3.85, S D=1.36)$ than women $(M=4.32, S D=1.22)$. Controlling for gender in the analyses testing the main hypotheses did not substantially alter the results, and subsequent analyses are reported without gender as a covariate.

\section{The Effect of Motivation on Willingness to Plan}

The main hypothesis in Experiment 2, as in Experiment 1 , concerned the effect of different motivational states on willingness to plan. Contrary to our main hypothesis, but in line with results from Experiment 1, there was no significant effect of experimental condition on willingness to plan, $t(785)=0.367, p=.714, d=0.03,95 \%$ CI [-0.140, 0.210].

Participants in the approach condition $(M=4.24, S D=$ 1.27) did not differ significantly from participants in the avoidance condition $(M=4.20, S D=1.26)$ in their selfreported willingness to plan. Thus, supporting the results from our first experiment, the different types of motivational states did not appear to influence participant's willingness to make plans. 


\section{Mediation Analysis}

In the next step, we conducted the pre-registered mediation analyses, as a significant main effect is not required for meaningful mediation to occur (Hayes, 2013; but see also Bullock et al., 2010). To test the specific mediation hypotheses in the current investigation, we performed a parallel mediation analysis $(n=787)$ using Model 4 in PROCESS (Hayes, 2013). Motivational state was entered as the independent variable, anticipated affect intensity and perceived distance were entered as the mediators, and willingness to plan as the dependent variable. The mediation hypotheses were tested with 10,000 bootstrap samples, and unstandardized effects are reported.

Participants in the approach condition reported a significantly greater intensity of anticipated affect than participants in the avoidance condition $\left(a^{1}=-1.20, p<.001,95 \%\right.$ CI $[-1.46,-0.95])$. Furthermore, greater intensity of anticipated affect was significantly associated with a higher willingness to plan $\left(b^{1}=0.10, p<.001,95 \%\right.$ CI $\left.[0.457,0.144]\right)$, meaning that high (vs low) intensity of anticipated affect from achieving a desired grade (vs getting an undesired grade) was positively correlated with willingness to plan. A bias-corrected bootstrap confidence interval for the indirect effect of motivational state through anticipated affect $\left(a b^{1}\right.$ $=-0.114$ ), holding the indirect effect through perceived distance constant, was significant (95\% CI [-0.188, -0.049]). As such, despite the absence of a significant main effect of motivational state on willingness to plan, there was a significant indirect effect through the intensity of anticipated affect. We note that this finding is different from our pre-registered mediational hypothesis, which pre-supposed a significant main effect on the outcome variable.

Motivational state had no significant effect on perceived distance $\left(a^{2}=-0.105, p=.59,95 \%\right.$ CI $\left.[-0.484,0.274]\right)$. Additionally, perceived distance was not significantly associated with willingness to plan $\left(b^{2}=-0.022, p=.18,95 \% \mathrm{CI}\right.$ $[-0.055,0.010])$, unlike what was found in Experiment 1 . A bias-corrected bootstrap confidence interval for the indirect effect of motivational state through perceived distance $\left(a b^{2}\right.$ $=0.002$ ), holding the indirect effect through anticipated affect intensity constant, was not significant $(95 \% \mathrm{CI}=-0.007$, 0.017). Thus, the effect of motivational state on willingness to plan was not mediated by perceived distance.

\section{Exploratory Analyses}

Participants in both the approach condition $(M=7.53, S D$ $=2.55)$ and the avoidance condition $(M=7.09, S D=2.59)$ experienced the goals they set as part of the experimental manipulation as being personally relevant. This suggests that the absence of a difference between groups cannot be explained by a lack of personal relevance. Predicted grades did not differ as a consequence of experimental condition, $t(779)=-0.091, p=.927, d=0.00,95 \%$ CI $[-0.130,0.120]$. Willingness to plan did not differ as a consequence of when participants completed the survey in relation to a lecture, $F(3,783)=0.697, p=.554, \eta_{p}^{2}=.003$. Negative mood did not differ as a consequence of when they completed the survey in relation to a lecture, $F(3,782)=1.86, p=.135, \eta_{\mathrm{p}}{ }^{2}$ $=.007$. However, positive mood differed according to when participants completed the survey: Participants who completed the survey in a lecture reported more positive mood $(M=5.97, S D=1.83)$ than participants who completed the survey preceding a lecture $(M=4.63, S D=2.18)$, after a lecture $(M=4.67, S D=1.64)$ or independently of a lecture $(M$ $=4.89, S D=1.93), F(3,783)=3.37, p=.018, \eta_{\mathrm{p}}^{2}=.013$. However, as noted earlier, there was no association between positive mood and willingness to plan.

Participants in the approach condition $(M=5.09, S D=$ 1.94) reported a significantly more positive mood at the end of the questionnaire than participants in the avoidance condition $(M=4.71, S D=1.91), t(785)=2.758, p=.006, d=0.20$, $95 \%$ CI $[0.110,0.650]$. However, the participants in the approach $(M=4.46, S D=2.21)$ and avoidance $(M=4.75, S D$ $=2.24$ ) conditions did not differ in terms of negative mood, suggesting that participants' negative self-reported feelings did not vary as a function of whether they focused on what they wanted to approach or what they wanted to avoid. Finally, independently of experimental condition, participants who reported that they were more focused on the grade they wanted to achieve/avoid also reported a greater willingness to plan, $r(787)=.17, p<.001$.

\section{General Discussion}

The current experiments explored approach and avoidance motivation as psychological antecedents to planning. Based on reviewed literature, we formulated two pre-registered, competing hypotheses prior to the data collections: 1) people are more willing to plan for what they want to approach than for what they want to avoid, and 2) people are more willing to plan for what they want to avoid than what they want to approach. Contrary to both predictions, there was no difference in the willingness to plan between participants in the two experimental conditions in either experiment, suggesting that people may not plan differently for what they want to approach compared to what they want to avoid.

Partly in line with our mediational hypothesis for anticipated affect as a process mechanism, participants in the approach condition in both experiments reported more intense anticipated affect than participants in the avoidance condition. However, only the results of Experiment 2 showed that this intensity was associated with greater willingness to plan, lending partial support for its importance as a mediator. Contrary to the hypothesis for perceived distance, there was no difference in perceived distance between participants in the two conditions in either experiment. Only in Experiment 1 did the results show that regardless of condition, perceived distance was associated with willingness to plan: Participants who experienced the day of the exam as closer were more willing to plan their future behavior. This lends little support to its role as a mediator.

Also, there was an unexpected (or at least non-predicted) gender difference in willingness to plan: Female participants were on average more willing to plan their study preparations than male participants. Despite a negligible gender difference in conscientiousness (Weisberg et al., 2011), some studies suggest that women have a greater planning ability than men (Naglieri \& Rojahn, 2001), and 
that men are slightly more impulsive than women (Cross et al., 2011). This difference might therefore be accounted for by general gender differences related to planning. When included as a covariate, however, this gender difference did not substantially alter the null results regarding the effect of motivational state on the willingness to plan.

\section{Motivational States and Willingness to Plan}

If motivational states do not influence planning, this could explain the lack of difference between the two experimental conditions on willingness to plan in the present experiments. However, this would be surprising considering the previous literature implying associations between approach and avoidance motivation and planning (e.g. Andre et al., 2017; Kaplan et al., 2009), and research showing the importance of approach and avoidance motivation for goal pursuit (Tamir \& Diener, 2008). Although one study found no effects of approach or avoidance goals on planning ability (Oertig et al., 2012), we would find it surprising if a person's motivational state did not have any meaningful effect on his or her willingness to make plans.

Alternatively, people may be equally willing to plan for approach and avoidance, also explaining the lack of a difference in willingness to plan between participants in the two conditions. The literature implying associations between approach and avoidance motivation and planning gave rise to competing, bi-directional hypotheses about the influence of motivational states on willingness to plan. An alternative interpretation is that approach and avoidance motivation influence planning equally (i.e., they both have a positive effect), meaning there would be no reason to expect a difference between the two experimental conditions. That is, it could be the case that the strength of motivational orientation matters more than the type. Providing a causal test of this hypothesis would have necessitated a neutral control group as a third condition, in addition to the two experimental groups. In such a design, we could not only have compared the relative strength of approach versus avoidance motivation, but also tested the individual effect of each as compared to a neutral baseline in third (control) condition. However, a conceptual reason for not including a control group is that it appears improbable for people to be "frameless" when they contemplate a goal. As the experimental manipulations were centered around motivational frames, and any control condition would therefore logically have to instruct people to be "frameless", control data is unlikely to represent a meaningful comparison. Thus, the most relevant experimental design to study the specific forms of approach and avoidance motivation addressed in the current research would involve two experimental groups. At least if the research question is concerned with the relative effect of each motivational orientation, this design should be able to detect a robust effect if there is one.

The aforementioned explanations are grounded in the assumption that approach and avoidance motivation influence planning independently. These effects could either be similarly negligible (i.e., the motivational states do not influence willingness to plan) or similarly important (i.e., both motivational states enhance willingness to plan compared to a control condition). A third option is that a combi- nation of the motivational states could influence planning. This would suggest that people may be more willing to plan if they focus on both what they seek to approach and what they seek to avoid, compared to focusing solely on either approach-related outcomes or avoidance-related outcomes. This could be comparable to the motivational effects of possible selves, a person's prospective thoughts about the person he or she might become in the future (Markus \& Ruvolo, 1989). Specifically, a balance between hoped-for selves and feared selves is assumed to create a greater motivational intensity than their independent effects. Somewhat related, research on goal pursuit suggests that people are most likely to succeed in long-term behavior change if they combine their action plan of what they want to achieve with a "mental contrast" with present reality (Oettingen, 2012).

Additionally, it is worth mentioning that changes to the experimental design might allow more fine-grained explorations of different kinds of motivational antecedents to how willing people are to plan. Prior studies (Lochbaum \& Gottardy, 2015) have explored the relationship between mastery and performance goals and performance, particularly in sports and physical activity, and have found a larger effect contrasting performance goals with mastery goals as compared to individual effects of approach goals. Thus, study designs more closely linked to the overall literature on different forms of achievement goals and their implications for performance, emphasizing other distinctions than the approach-avoidance distinction, may be relevant in the further study of motivational antecedents of planning beyond the approach-avoidance contrast.

Finally, it is worth addressing the possibility that the experimental manipulations were ineffective in activating approach and avoidance motivation. While there is more uncertainty connected to interpreting the validity of the manipulation in Experiment 1, the sample size and the results from the novel manipulation check in Experiment 2 support that the manipulation worked as intended in both experiments. Although the manipulation seemed to be considerably more effective in inducing approach motivation than avoidance motivation, the results support the assumption that participants were indeed induced to distinct motivational states. Thus, we regard our experiments as appropriate tests of the specific hypotheses in the current investigation.

\section{Anticipated Affect and Perceived Distance}

In both experiments, participants in the approach condition predicted significantly more intense affect than participants in the avoidance condition. More intense anticipated affect for what people want to approach compared to what they want to avoid runs counter to the widespread pattern that "bad is stronger than good" (Baumeister et al., 2001). However, anticipated affect was only associated with willingness to plan in Experiment 2. One explanation for this may be that the increase in statistical power allowed us to detect a smaller, indirect effect that could not be detected in Experiment 1 . The association with willingness to plan is in line with assumptions that different forms of future thinking, such as predictions and planning, may be intimately associated with each other (Szpunar et al., 2014). 
There was no effect of motivational states on perceived distance, suggesting that perceptions of temporal distance are not influenced by whether people focus on what they want to approach or what they want to avoid. Given the assumed importance of approach and avoidance motivation for perceptions of distance (Balcetis, 2016), this is rather surprising and suggests that motivational states may be less important for some forms of psychological distance. However, Experiment 1 suggests that perceived distance might be a potential mechanism in the psychology of planning, as the results showed an associated between shorter perceived distance and greater willingness to plan. Although this initial finding was not replicated in our second experiment, it is congruent with research suggesting greater motivation for outcomes which are perceived as temporally closer (Peetz et al., 2009).

\section{Limitations}

Manipulation of motivational states. One contention related to the manipulation of motivational states is that the use of outcome framing as an experimental manipulation may not be an effective way to manipulate motivational states. Indeed, based on prior research, one could argue that using participants' ideographic goals is more suitable and would produce a stronger experimental effect (e.g. Dickson \& MacLeod, 2004, 2006). However, outcome framing has been used successfully previously, and it is reasonable to argue that participants, while having idiographic goals, are also able to think about situational approach and avoidance goals. Therefore, we argue that the experimental manipulation, as a way of manipulating approach and avoidance motivational states, is suitable in the context in which the experiments were conducted.

Measures. There was a difference in the internal consistency for scores on the action planning measure in the current experiments and the test values commonly reported in the literature (Darker et al., 2010). One explanation for this difference is a lack of factorial invariance (Fabrigar \& Wegener, 2016), a concept covering similarities in the constructs measured in different studies. This would suggest that the measure of planning did not assess the intended construct. However, the composition of action planning might depend on several different variables, including the context in which it is measured. For example, some students may generally read at the same study space. As a consequence, they might not be as willing to plan for where they are going to read as for when, how, and how long they are going to read. This would explain why there was no strong association between scores on the item measuring planning for where to read (the item that was removed from the scale) and scores on the other items in Experiment 1. Such context dependency has also been shown in other studies (Åstrøm, 2008). In conclusion, there are legitimate reasons to suspect that the modest reliability of the planning measure was due to the context in which it was applied, rather than to the measure not accurately reflecting willingness to plan.

Another methodological consideration is the operationalization of anticipated affect intensity. Participants in the approach condition were asked how they would feel if their goal was achieved, whereas participants in the avoidance condition were asked how they would feel if they failed to avoid what they aimed to avoid. An obvious alternative would be to ask participants in the avoidance condition how they would feel if they managed to avoid the undesirable outcome. However, we argue that our conceptualization of anticipated affect resonates with the assumption that approach motivation is linked to anticipated positive affect and avoidance motivation to anticipated negative affect, meaning that pursuing avoidance goals is more closely linked to attempting to avoid anticipated negative feelings than attempting to attain anticipated positive feelings.

A statistical contention to the measurement of anticipated affect concerns how the scores were calculated. We assessed both positive and negative anticipated affect intensity by reversing the values in the avoidance condition. Prior research suggests that certain biases may be stronger for anticipated negative affect than anticipated positive affect, such that the difference between anticipated affect and experienced affect (impact bias) is stronger and more consistent for negative affect (e.g. Gilbert et al., 1998). However, this does not imply that anticipated negative affect is more intense than anticipated positive affect. Thus, there are legitimate grounds for measuring anticipated affect intensity in the way in which it was done in these experiments.

Finally, there is some controversy regarding the reliability of one-item measures, which has implications for the measurement of anticipated affect and perceived distance. However, one-item measures of anticipated affect have been shown to correlate substantially with multi-item measures of anticipated affect (Gilbert et al., 1998), supporting the use of one-item measures for anticipated affect. Furthermore, one-item measures are very commonly used in the literature on anticipated affect (Gilbert et al., 1998; Greitemeyer, 2009; Greitemeyer et al., 2011; Morewedge \& Buechel, 2013). Also, one-item measures of perceived distance are widely used in studying both prospective (Lee \& Ji, 2014; Peetz et al., 2009) and retrospective (Mei et al., 2018; Siedlecka et al., 2015) perceptions of psychological distance, meaning that the current experiments are at least not more susceptible to this criticism than other studies in the field.

\section{Future Research and Implications}

Future research. If approach and avoidance motivation influence willingness to plan relatively equally, future studies could include an experimental condition combining both motivational states in addition to one experimental condition for each motivational state to assess the potential combined effects of approach and avoidance. Changes to the experimental design are also relevant for further exploring the relationship between anticipated affect and willingness to plan. For example, even if there is some support for anticipated affect intensity as a causal mechanism from the current experiments, how people expect to feel about planning (the process) may be more important than what they expect to feel about the goal (the outcomes). This reflects the conceptual distinction between anticipated affective responses to process versus outcome (Kwong et al., 2013).

As both perceived distance and willingness to plan were 
measured, further research manipulating one or both mediators would be better suited to assess their influence on planning. For example, experimentally manipulating the intensity of anticipated affect would illuminate the role of affective predictions as precursors for planning. The same is the case for perceived distance: If participants induced to experience the future as closer also report a greater willingness to plan their behavior, this would suggest an influence of perceived temporal distance on planning.

Additionally, action planning represents only one form of planning, distinct from other forms such as coping planning (Sniehotta et al., 2005). Whether motivational states influence other forms of planning similarly to their apparent (lacking) effects on action planning remains an open question. For example, people may be differently willing to plan for meeting obstacles during goal pursuit (coping planning) depending on whether they focus on what they want to approach or what they want to avoid.

Implications. Approach and avoidance motivation are assumed to have important, but different, effects on goal striving (Elliot \& Church, 1997; Oertig et al., 2013; Tamir \& Diener, 2008). The current results suggest that motivational states may not have independent, different effects on how willing people are to plan their behavior. Also, even though approach and avoidance motivation are assumed to influence psychological distance (Balcetis, 2016), the results from these experiments suggest that the relative difference of approach versus avoidance motivation may not be as influential for perceived temporal distance. This suggests that there are limits to the similarities between different forms of psychological distance: motivational states may influence some forms, but not all forms, of psychological distance.

Regarding planning, the results suggest that different motivational states may not be as influential in the psychology of planning as other motivational antecedents. Even though planning may be influenced by beliefs (Day \& Maltby, 2005; Kreitler \& Kreitler, 1987), perceptions of control (Doron et al., 2009; S. L. Friedman et al., 1987) and self-control (Sjåstad \& Baumeister, 2018), motivational states may be less important in explaining why people plan.

If people are not differentially willing to plan while experiencing different motivational states, this suggests that people can fruitfully use both what they want to approach and what they want to avoid when making plans. Alternatively, if motivational states do not influence willingness to plan, it suggests that other strategies may be more useful. For example, reducing the perceived temporal distance to outcomes or increasing the intensity of the anticipated affect connected to these outcomes may be more influential in stimulating future planning. Further research is necessary to explore the role of perceived temporal distance and anticipated affect intensity as causal influences on plan- ning.

Conclusion. The current experiments were designed to add to our understanding of why people choose to plan. Based on a review of relevant literature, we hypothesized that there could be a stronger effect of either approach or avoidance motivation on willingness to plan and conducted two experiments to test these hypotheses. Anticipated affect and perceived temporal distance were two potential mechanisms proposed to explain an effect of these motivational states on willingness to plan.

The results favor the null hypotheses, both for the main effect and for the mediational effects. However, we did find suggestive evidence for the importance of anticipated affect as a process mechanism in planning decisions, although such mediational findings without a causal main effect on the outcome measure should be interpreted with caution. Seen as a whole, this suggests that approach and avoidance motivation might have different effects than what was originally assumed. The results from these experiments may aid researchers in setting goals for future research, and ultimately, to make plans of their own.

\section{Contributions}

SB, EN and HS contributed to conception and design, interpretation of data, drafted and revised the article and approved the submitted version for publication. SB and HS contributed to analysis. SB contributed to acquisition of data.

\section{Acknowledgements}

The conducted research was preregistered with analyses plans at http://aspredicted.org , and adheres to the disclosure agreements at this registry. The pre-registrations are available in the appendices.

\section{Competing Interests}

No competing interests exist.

\section{Data Accessibility Statement}

All the material can be found on this page's project page on Open Science Framework (https://osf.io/ neyg6/?view_only=16d0fd4a26814f10afeea2f68fde97bd).

Submitted: November 25, 2019 PST, Accepted: February 15, 2021 PST 


\section{REFERENCES}

Aaker, J. L., \& Lee, A. Y. (2001). "I” seek pleasures and "we" avoid pains: The role of self-regulatory goals in information processing and persuasion. Journal of Consumer Research, 28(1), 33-49. https://doi.org/10.1 $\underline{086 / 321946}$

Aarts, H., Ruys, K. I., Veling, H., Renes, R. A., de Groot, J. H. B., van Nunen, A. M., \& Geertjes, S. (2010). The art of anger: Reward context turns avoidance responses to anger-related objects into approach. Psychological Science, 21(10), 1406-1410. ht tps://doi.org/10.1177/0956797610384152

Andre, L., van Vianen, A. E. M., \& Peetsma, T. T. D. (2017). Adolescents' and parents' regulatory focus as determinants of future time perspective on school and professional career. Learning and Individual Differences, 59, 34-42. https://doi.org/10.1016/j.lindi $\underline{\text { f.2017.08.010 }}$

Åstrøm, A. N. (2008). Applicability of action planning and coping planning to dental flossing among Norwegian adults: A confirmatory factor analysis approach. European Journal of Oral Sciences, 116(3), 250-259. https://doi.org/10.1111/j.1600-0722.2008.0 0538.x

Balcetis, E. (2016). Approach and avoidance as organizing structures for motivated distance perception. Emotion Review, 8(2), 115-128. https://do i.org/10.1177/1754073915586225

Baumeister, R. F., Bratslavsky, E., Finkenauer, C., \& Vohs, K. D. (2001). Bad is stronger than good. Review of General Psychology, 5(4), 323-370. https://doi.org/1 $\underline{0.1037 / 1089-2680.5 .4 .323}$

Baumeister, R. F., Maranges, H. M., \& Sjåstad, H. (2018). Consciousness of the future as a matrix of maybe: Pragmatic prospection and the simulation of alternative possibilities. Psychology of Consciousness: Theory, Research, and Practice, 5(3), 223-238. http s://doi.org/10.1037/cns0000154

Bullock, J. G., Green, D. P., \& Ha, S. E. (2010). Yes, but what's the mechanism? (don't expect an easy answer). Journal of Personality and Social Psychology, 98(4), 550-558. https://doi.org/10.1037/a0018933

Carraro, N., \& Gaudreau, P. (2011). Implementation planning as a pathway between goal motivation and goal progress for academic and physical activity goals. Journal of Applied Social Psychology, 41(8), 1835-1856. https://doi.org/10.1111/j.1559-1816.201 1.00795.x
Chan, C. K. Y., \& Cameron, L. D. (2012). Promoting physical activity with goal-oriented mental imagery: A randomized controlled trial. Journal of Behavioral Medicine, 35(3), 347-363. https://doi.org/10.1007/s10 865-011-9360-6

Coats, E. J., Janoff-Bulman, R., \& Alpert, N. (1996). Approach versus avoidance goals: Differences in selfevaluation and well-being. Personality and Social Psychology Bulletin, 22(10), 1057-1067. https://doi.or $\mathrm{g} / 10.1177 / 01461672962210009$

Crawford, M. T., McCarthy, R. J., Kjærstad, H. L., \& Skowronski, J. J. (2013). Inferences are for doing: The impact of approach and avoidance states on the generation of spontaneous trait inferences. Personality and Social Psychology Bulletin, 39(3), 267-278. https://doi.org/10.1177/0146167212473158

Cross, C. P., Copping, L. T., \& Campbell, A. (2011). Sex differences in impulsivity: A meta-analysis. Psychological Bulletin, 137(1), 97-130. https://doi.org/ 10.1037/a0021591

D’Argembeau, A., Renaud, O., \& Van der Linden, M. (2011). Frequency, characteristics and functions of future-oriented thoughts in daily life. Applied Cognitive Psychology, 25(1), 96-103. https://doi.org/1 $\underline{0.1002 / \text { acp. } 1647}$

Darker, C. D., French, D. P., Eves, F. F., \& Sniehotta, F. F. (2010). An intervention to promote walking amongst the general population based on an 'extended' theory of planned behaviour: A waiting list randomised controlled trial. Psychology \& Health, 25(1), 71-88. https://doi.org/10.1080/0887044090289 $\underline{3716}$

Das, G. (2015). Retail shopping behaviour: Understanding the role of regulatory focus theory. The International Review of Retail, Distribution and Consumer Research, 25(4), 431-445. https://doi.org/1 $\underline{0.1080 / 09593969.2015 .1017773}$

Day, L., \& Maltby, J. (2005). “With Good Luck”: Belief in good luck and cognitive planning. Personality and Individual Differences, 39(7), 1217-1226. https://doi.or g/10.1016/i.paid.2005.04.011

Detweiler-Bedell, J. B., \& Salovey, P. (2003). Striving for happiness or fleeing from sadness? Motivating mood repair using differentially framed messages. Journal of Social and Clinical Psychology, 22(6), 627-664. https://doi.org/10.1521/jscp.22.6.627.22935 
DeWall, C. N., Baumeister, R. F., Chester, D. S., \& Bushman, B. J. (2016). How often does currently felt emotion predict social behavior and judgment? A meta-analytic test of two theories. Emotion Review, 8(2), 136-143. https://doi.org/10.1177/175407391557 $\underline{2690}$

Dewhurst, S. A., Anderson, R. J., Grace, L., \& Howe, D. (2019). Simulation, false memories, and the planning of future events. Journal of Experimental Psychology: Learning, Memory, and Cognition, 45(1), 26-36. https://doi.org/10.1037/xlm0000575

Dickson, J. M., \& MacLeod, A. K. (2004). Approach and avoidance goals and plans: Their relationship to anxiety and depression. Cognitive Therapy and Research, 28(3), 415-432. https://doi.org/10.1023/b:c otr.0000031809.20488.ee

Dickson, J. M., \& MacLeod, A. K. (2006). Dysphoric adolescents' causal explanations and expectancies for approach and avoidance goals. Journal of Adolescence, 29(2), 177-191. https://doi.org/10.1016/j.adolescenc e.2005.03.007

Doron, J., Stephan, Y., Boiché, J., \& Scanff, C. L. (2009). Coping with examinations: Exploring relationships between students' coping strategies, implicit theories of ability, and perceived control. British Journal of Educational Psychology, 79(3), 515-528. https://doi.org/10.1348/978185409x402580

Elliot, A. J. (2006). The hierarchical model of approach-avoidance motivation. Motivation and Emotion, 30(2), 111-116. https://doi.org/10.1007/s110 31-006-9028-7

Elliot, A. J. (2008). Handbook of approach and avoidance motivation. Psychology Press.

Elliot, A. J., \& Church, M. A. (1997). A hierarchical model of approach and avoidance achievement motivation. Journal of Personality and Social Psychology, 72(1), 218-232. https://doi.org/10.1037/0 $\underline{022-3514.72 .1 .218}$

Ellis, S., \& Siegler, R. S. (1997). Planning as a strategy choice, or why don't children plan when they should? In S. L. Friedman \& E. K. Scholnick (Eds.), The developmental psychology of planning: Why, how, and when do we plan? (pp. 183-208). Lawrence Erlbaum Associates.

Fabrigar, L. R., \& Wegener, D. T. (2016). Conceptualizing and evaluating the replication of research results. Journal of Experimental Social Psychology, 66, 68-80. https://doi.org/10.1016/i.jesp.2 $\underline{015.07 .009}$
Faul, F., Erdfelder, E., Lang, A.-G., \& Buchner, A. (2007). G*Power 3: A flexible statistical power analysis program for the social, behavioral, and biomedical sciences. Behavior Research Methods, 39(2), 175-191. https://doi.org/10.3758/bf03193146

Friedman, R. S., \& Förster, J. (2000). The effects of approach and avoidance motor actions on the elements of creative insight. Journal of Personality and Social Psychology, 79(4), 477-492. https://doi.org/10.1 $\underline{037 / 0022-3514.79 .4 .477}$

Friedman, S. L., Scholnick, E. K., \& Cocking, R. R. (1987). Blueprints for thinking. Cambridge University Press.

Gilbert, D. T., Pinel, E. C., Wilson, T. D., Blumberg, S. J., \& Wheatley, T. P. (1998). Immune neglect: A source of durability bias in affective forecasting. Journal of Personality and Social Psychology, 75(3), 617-638. https://doi.org/10.1037/0022-3514.75.3.617

Glatston, A. R. (1994). Status survey and conservation action plan for procyonids and ailurids: The red panda, olingos, coatis, raccoons and their relatives.

International Union for Conservation of Nature and Natural Resources.

Gollwitzer, P. M. (1996). The volitional benefits of planning. In P. M. Gollwitzer \& J. A. Bargh (Eds.), The psychology of action: Linking cognition and motivation to behavior (pp. 287-312). Guilford Press.

Gollwitzer, P. M., \& Sheeran, P. (2006).

Implementation intentions and goal achievement: A meta - analysis of effects and processes. Advances in Experimental Social Psychology, 38, 69-119. https://do i.org/10.1016/s0065-2601(06)38002-1

Greitemeyer, T. (2009). The effect of anticipated affect on persistence and performance. Personality and Social Psychology Bulletin, 35(2), 172-186. http s://doi.org/10.1177/0146167208326124

Greitemeyer, T., Lebek, S., Frey, D., \& TrautMattausch, E. (2011). Why people try to actively change unchangeable situations: The role of anticipated affect. Current Psychology, 30(3), 284-298. https://doi.org/10.1007/s12144-011-9113-2

Hagger, M. S., \& Luszczynska, A. (2014). Implementation intention and action planning interventions in health contexts: State of the research and proposals for the way forward. Applied Psychology: Health and Well-Being, 6(1), 1-47. http s://doi.org/10.1111/aphw.12017

Hales, A. H. (2016). Does the conclusion follow from the evidence? Recommendations for improving research. Journal of Experimental Social Psychology, 66, 39-46. https://doi.org/10.1016/i.jesp.2015.09.011 
Harmon-Jones, E. (2003). Anger and the behavioral approach system. Personality and Individual Differences, 35(5), 995-1005. https://doi.org/10.1016/ s0191-8869(02)00313-6

Hayes, A. F. (2009). Beyond Baron and Kenny: Statistical mediation analysis in the new millennium. Communication Monographs, 76(4), 408-420. https://d oi.org/10.1080/03637750903310360

Hayes, A. F. (2013). Introduction to mediation, moderation, and conditional process analysis: $A$ regression-based approach. Guilford Press.

Hayes-Roth, B., \& Hayes-Roth, F. (1979). A cognitive model of planning. Cognitive Science, 3(4), 275-310. h ttps://doi.org/10.1016/s0364-0213(79)80010-5

Higgins, E. T. (1996). Promotion and prevention: Regulatory focus as a motivational principle. In M. P. Zanna (Ed.), Advances in experimental social psychology (Vol. 30, pp. 1-46). Academic Press.

Higgins, E. T. (2012). Regulatory focus theory. In P. A. M. Van Lange, A. W. Kruglansi, \& E. T. Higgins (Eds.), Handbook of Theories of Social Psychology (Vol. 1, pp. 483-504). SAGE Publications Ltd. https://doi.org/10.4 135/9781446249215.n24

Higgins, E. T., \& Spiegel, S. (2004). Promotion and prevention strategies for self-regulation: A motivated cognition perspective. In R.F. Baumeister \& K. D. Vohs (Eds.), Handbook of self-regulation: Research, theory and applications (pp. 171-189). Guilford Press.

Kaplan, A., Lichtinger, E., \& Gorodetsky, M. (2009). Achievement goal orientations and self-regulation in writing: An integrative perspective. Journal of Educational Psychology, 101(1), 51-69. https://doi.org/ $\underline{10.1037 / \mathrm{a} 0013200}$

Kreitler, H., \& Kreitler, S. (1987). The motivational and cognitive determinants of individual planning. Genetic, Social, and General Psychology Monographs, 113(1), 83-107. https://www.tandfonline.com/loi/vzp $\underline{\mathrm{m} 20 /}$

Kwong, J. Y. Y., Wong, K. F. E., \& Tang, S. K. Y. (2013). Comparing predicted and actual affective responses to process versus outcome: An emotion-as-feedback perspective. Cognition, 129(1), 42-50. https://doi.org/ 10.1016/j.cognition.2013.05.012

Lee, A., \& Ji, L.-J. (2014). Moving away from a bad past and toward a good future: Feelings influence the metaphorical understanding of time. Journal of Experimental Psychology: General, 143(1), 21-26. http s://doi.org/10.1037/a0032233
Li, Y. J., Kenrick, D. T., Griskevicius, V., \& Neuberg, S. L. (2012). Economic decision biases and fundamental motivations: How mating and self-protection alter loss aversion. Journal of Personality and Social Psychology, 102(3), 550-561. https://doi.org/10.1037/ a0025844

Lochbaum, M., \& Gottardy, J. (2015). A meta-analytic review of the approach-avoidance achievement goals and performance relationships in the sport psychology literature. Journal of Sport and Health Science, 4(2), 164-173. https://doi.org/10.1016/j.jsh $\underline{\mathrm{s} .2013 .12 .004}$

Markus, H., \& Ruvolo, A. (1989). Possible selves: Personalized representations of goals. In L. A. Pervin (Ed.), Goal concepts in personality and social psychology (pp. 211-241). Lawrence Erlbaum Associates.

Mattila, A. S., \& Wirtz, J. (2001). Congruency of scent and music as a driver of in-store evaluations and behavior. Journal of Retailing, 77(2), 273-289. http s://doi.org/10.1016/s0022-4359(01)00042-2

Mehta, A., Feild, H., Armenakis, A., \& Mehta, N. (2009). Team goal orientation and team performance: The mediating role of team planning. Journal of Management, 35(4), 1026-1046. https://doi.org/10.11 77/0149206308326773

Mei, D., Li, L. M. W., \& Wang, Y. (2018). Influence of emotional valence on perceived psychological distance depends on emotional intensity. European Journal of Social Psychology, 48(5), 687-700. https://do i.org/10.1002/ejsp.2361

Mellers, B., Schwartz, A., \& Ritov, I. (1999). Emotionbased choice. Journal of Experimental Psychology: General, 128(3), 332-345. https://doi.org/10.1037/009 6-3445.128.3.332

Meltzoff, J., \& Cooper, H. (2018). Critical thinking about research: Psychology and related fields (2nd ed.). American Psychological Association.

Miloyan, B., \& Suddendorf, T. (2015). Feelings of the future. Trends in Cognitive Sciences, 19(4), 196-200. ht tps://doi.org/10.1016/i.tics.2015.01.008

Moos, D. C., \& Azevedo, R. (2006). The role of goal structure in undergraduates' use of self-regulatory processes in two hypermedia learning tasks. Journal of Educational Multimedia and Hypermedia, 15(1), 49-86. https://www.aace.org/pubs/jemh/

Morewedge, C. K., \& Buechel, E. C. (2013). Motivated underpinnings of the impact bias in affective forecasts. Emotion, 13(6), 1023-1029. https://doi.org/ $\underline{10.1037 / \mathrm{e} 621072012-254}$ 
Mumford, M. D., Schultz, R. A., \& Van Doorn, J. R. (2001). Performance in planning: Processes, requirements, and errors. Review of General Psychology, 5(3), 213-240. https://doi.org/10.1037/10 89-2680.5.3.213

Naglieri, J. A., \& Rojahn, J. (2001). Gender differences in planning, attention, simultaneous, and successive (PASS) cognitive processes and achievement. Journal of Educational Psychology, 93(2), 430-437. https://do i.org/10.1037/0022-0663.93.2.430

Nelson, L. D., Simmons, J., \& Simonsohn, U. (2018). Psychology's renaissance. Annual Review of Psychology, 69(1), 511-534. https://doi.org/10.1146/a nnurev-psych-122216-011836

Oertig, D., Schüler, J., \& Brandstätter, V. (2012). Do avoidance goals always impair performance? How neuroticism moderates the short- and long-term effects of avoidance versus approach goals on performance. In A. L. Magnusson \& D. J. Lindberg (Eds.), Psychology of performance and defeat (pp. 111-132). Nova Science Publishers.

Oertig, D., Schüler, J., Schnelle, J., Brandstätter, V., Roskes, M., \& Elliot, A. J. (2013). Avoidance goal pursuit depletes self-regulatory resources. Journal of Personality, 81(4), 365-375. https://doi.org/10.1111/jo py.12019

Oettingen, G. (2012). Future thought and behaviour change. European Review of Social Psychology, 23(1), 1-63. https://doi.org/10.1080/10463283.2011.643698

O’Hara, K. P., \& Payne, S. J. (1998). The effects of operator implementation cost on planfulness of problem solving and learning. Cognitive Psychology, 35(1), 34-70. https://doi.org/10.1006/cogp.1997.0676

Orne, M. T. (1962). On the social psychology of the psychological experiment: With particular reference to demand characteristics and their implications. American Psychologist, 17(11), 776-783. https://doi.or $\mathrm{g} / 10.1037 / \mathrm{h} 0043424$

Papaioannou, A. G., Simou, T., Kosmidou, E., Milosis, D., \& Tsigilis, N. (2009). Goal orientations at the global level of generality and in physical education: Their association with self-regulation, affect, beliefs and behaviours. Psychology of Sport and Exercise, 10(4), 466-480. https://doi.org/10.1016/j.psychspor t.2009.01.003

Park, J., Lu, F.-C., \& Hedgcock, W. M. (2017). Relative effects of forward and backward planning on goal pursuit. Psychological Science, 28(11), 1620-1630. http s://doi.org/10.1177/0956797617715510
Parkinson, C., Liu, S., \& Wheatley, T. (2014). A common cortical metric for spatial, temporal, and social distance. Journal of Neuroscience, 34(5), 1979-1987. https://doi.org/10.1523/jneurosci.2159-1 $\underline{3.2014}$

Peetz, J., Wilson, A. E., \& Strahan, E. J. (2009). So far away: The role of subjective temporal distance to future goals in motivation and behavior. Social Cognition, 27(4), 475-495. https://doi.org/10.1521/soc $\underline{0.2009 .27 .4 .475}$

Peng, A. C., Dunn, J., \& Conlon, D. E. (2011). When vigilance prevails: Regulatory focus in negotiations with external goals. 24th Annual International Association of Conflict Management Conference, Istanbul. http s://doi.org/10.2139/ssrn.1872558

Pervin, L. A. (1989). Goal concepts in personality and social psychology. Lawrence Erlbaum Associates.

Phillips, L. H., Smith, L., \& Gilhooly, K. J. (2002). The effects of adult aging and induced positive and negative mood on planning. Emotion, 2(3), 263-272. $\underline{\mathrm{h}}$ ttps://doi.org/10.1037/1528-3542.2.3.263

Pintrich, P. R., Smith, D. A. F., Garcia, T., \& McKeachie, W. J. (1991). A manual for the use of the Motivated Strategies for Learning Questionnaire (MSLQ) (Tech. Report No. 91 B-004). The Regents of The University of Michigan.

Pintrich, P. R., Smith, D. A. F., Garcia, T., \& McKeachie, W. J. (1993). Reliability and predictive validity of the Motivated Strategies for Learning Questionnaire (MSLQ). Educational and Psychological Measurement, 53(3), 801-813. https://doi.org/10.117 7/0013164493053003024

Ponterotto, J. G., \& Ruckdeschel, D. E. (2007). An overview of coefficient alpha and a reliability matrix for estimating adequacy of internal consistency coefficients with psychological research measures. Perceptual and Motor Skills, 105(3), 997-1014. http s://doi.org/10.2466/pms.105.3.997-1014

Prenda, K. M., \& Lachman, M. E. (2001). Planning for the future: A life management strategy for increasing control and life satisfaction in adulthood. Psychology and Aging, 16(2), 206-216. https://doi.org/10.1037/08 82-7974.16.2.206

Rhoden, C., \& West, J. (2010). Affect in sporting activities: A preliminary validation of the Worcester Affect Scale. Sport Science Review, 19(5-6), 71-91. htt ps://doi.org/10.2478/v10237-011-0033-8 
Roskes, M., De Dreu, C. K. W., \& Nijstad, B. A. (2012). Necessity is the mother of invention: Avoidance motivation stimulates creativity through cognitive effort. Journal of Personality and Social Psychology, 103(2), 242-256. https://doi.org/10.1037/a0028442

Scholnick, E. K., \& Friedman, S. L. (1993). Planning in context: Developmental and situational considerations. International Journal of Behavioral Development, 16(2), 145-167. https://doi.org/10.1177/ $\underline{016502549301600204}$

Seligman, M. E. P., Railton, P., Baumeister, R. F., \& Sripada, C. (2013). Navigating into the future or driven by the past. Perspectives on Psychological Science, 8(2), 119-141. https://doi.org/10.1177/17456 $\underline{91612474317}$

Siedlecka, E., Capper, M. M., \& Denson, T. F. (2015). Negative emotional events that people ruminate about feel closer in time. PLOS One, 10(2), e0117105. https://doi.org/10.1371/journal.pone.0117105

Sjåstad, H., \& Baumeister, R. F. (2018). The future and the will: Planning requires self-control, and ego depletion leads to planning aversion. Journal of Experimental Social Psychology, 76, 127-141. https://d oi.org/10.1016/j.jesp.2018.01.005

Sniehotta, F. F., Schwarzer, R., Scholz, U., \& Schüz, B. (2005). Action planning and coping planning for longterm lifestyle change: Theory and assessment.

European Journal of Social Psychology, 35(4), 565-576. https://doi.org/10.1002/ejsp.258

Spangenberg, E. R., Sprott, D. E., Grohmann, B., \& Tracy, D. L. (2006). Gender-congruent ambient scent influences on approach and avoidance behaviors in a retail store. Journal of Business Research, 59(12), 1281-1287. https://doi.org/10.1016/j.jbusres.2006.0 $\underline{8.006}$

Stawarczyk, D., Cassol, H., \& D’Argembeau, A. (2013). Phenomenology of future-oriented mind-wandering episodes. Frontiers in Psychology, 4, 1-12. https://do i.org/10.3389/fpsyg. 2013.00425

Summerville, A., \& Roese, N. J. (2008). Self-report measures of individual differences in regulatory focus: A cautionary note. Journal of Research in Personality, 42(1), 247-254. https://doi.org/10.1016/i.j rp.2007.05.005
Szpunar, K. K., Spreng, R. N., \& Schacter, D. L. (2014). A taxonomy of prospection: Introducing an organizational framework for future-oriented cognition. Proceedings of the National Academy of Sciences, 111(52), 18414-18421. https://doi.org/10.10 73/pnas.1417144111

Tamir, M., \& Diener, E. (2008). Approach-avoidance goals and well-being: One size does not fit all. In A.J. Elliot (Ed.), Handbook of approach and avoidance motivation (pp. 415-428). Psychology Press.

Trope, Y., \& Liberman, N. (2010). Construal-level theory of psychological distance. Psychological Review, 117(2), 440-463. https://doi.org/10.1037/a0018963

Vartanian, L. R., Herman, C. P., \& Polivy, J. (2006). Does regulatory focus play a role in dietary restraint? Eating Behaviors, 7(4), 333-341. https://doi.org/10.10 16/j.eatbeh.2005.11.007

Ward, G., \& Morris, R. (2005). Introduction to the psychology of planning. In R. Morris \& G. Ward (Eds.), The cognitive psychology of planning (pp. 1-34). Psychology Press.

Weisberg, Y. J., DeYoung, C. G., \& Hirsh, J. B. (2011). Gender differences in personality across the ten aspects of the Big Five. Frontiers in Psychology, 2, 1-11. https://doi.org/10.3389/fpsyg.2011.00178

Wilson, T. D., \& Gilbert, D. T. (2005). Affective forecasting: Knowing what to want. Current Directions in Psychological Science, 14(3), 131-134. https://doi.or $\mathrm{g} / 10.1111 / \mathrm{j} .0963-7214.2005 .00355 . \mathrm{x}$

Winch, A., Moberly, N. J., \& Dickson, J. M. (2015). Unique associations between anxiety, depression and motives for approach and avoidance goal pursuit. Cognition and Emotion, 29(7), 1295-1305. https://do i.org/10.1080/02699931.2014.976544

World Medical Association. (2013). WMA declaration of Helsinki: Ethical principles for medical research involving human subjects. https://www.wma.net/polici es-post/wma-declaration-of-helsinki-ethical-principl es-for-medical-research-involving-human-subjects/ 


\section{SUPPLEMENTARY MATERIALS}

\section{Peer review history}

Download: https://collabra.scholasticahq.com/article/21173-working-for-the-best-or-bracing-for-the-worstapproach-and-avoidance-motivation-in-planning/attachment/53603.docx?auth_token=K4DELGRW9Z8ZKvKYWi5P

\section{Appendix S1: Pre-registration for Experiment 1}

Download: https://collabra.scholasticahq.com/article/21173-working-for-the-best-or-bracing-for-the-worstapproach-and-avoidance-motivation-in-planning/attachment/53606.pdf?auth token=K4DELGRW9Z8ZKvKYWi5P

\section{Appendix S2: Pre-registration for Experiment 2}

Download: https://collabra.scholasticahq.com/article/21173-working-for-the-best-or-bracing-for-the-worstapproach-and-avoidance-motivation-in-planning/attachment/53936.pdf?auth token=K4DELGRW9Z8ZKvKYWi5P

\section{Appendix S3: Deviations from the Pre-registrations}

Download: https://collabra.scholasticahq.com/article/21173-working-for-the-best-or-bracing-for-the-worstapproach-and-avoidance-motivation-in-planning/attachment/53938.docx?auth_token=K4DELGRW9Z8ZKVKYWi5P 